\title{
Cell Volume Regulation Mechanisms in Differentiated Astrocytes
}

\author{
Maria Grazia Mola ${ }^{a}$ Emanuela Saracino ${ }^{b}$ Francesco Formaggio ${ }^{c}$ \\ Arcangela Gabriella Amerottia, ${ }^{a}$ Barbara Barile ${ }^{a}$ Tamara Posati ${ }^{b}$

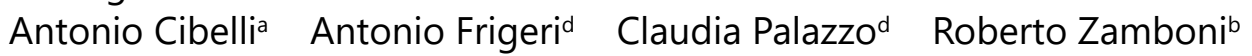 \\ Marco Caprinic Grazia Paola Nicchia ${ }^{a}$ Valentina Benfenati ${ }^{b}$
}

aDepartment of Biosciences, Biotechnologies and Biopharmaceutics, University of Bari Aldo Moro, Bari, Italy, ${ }^{b}$ Consiglio Nazionale delle Ricerche (CNR), Istituto per lo Sintesi Organica e la Fotoreattività (ISOF), Bologna, Italy, 'Department of Pharmacy and Biotechnology, University of Bologna, Bologna, Italy, ${ }^{d}$ Department of Basic Medical Sciences, Neurosciences and Sense Organs, School of Medicine, University of Bari Aldo Moro, Bari, Italy

\section{Key Words}

Astrocytes • Volume regulation $\cdot$ AQP4 and ion channels • Differentiation • Bio-nanomaterials

\begin{abstract}
Background/Aims: The ability of astrocytes to control extracellular volume homeostasis is critical for brain function and pathology. Uncovering the mechanisms of cell volume regulation by astrocytes will be important for identifying novel therapeutic targets for neurological conditions, such as those characterized by imbalances to hydro saline challenges (as in edema) or by altered cell volume regulation (as in glioma). One major challenge in studying the astroglial membrane channels involved in volume homeostasis in cell culture model systems is that the expression patterns of these membrane channels do not resemble those observed in vivo. In our previous study, we demonstrated that rat primary astrocytes grown on nanostructured interfaces based on hydrotalcite-like compounds (HTlc) in vitro are differentiated and display molecular and functional properties of in vivo astrocytes, such as the functional expression of inwardly rectifying $\mathrm{K}^{+}$channel (Kir 4.1) and Aquaporin-4 (AQP4) at the astrocytic microdomain. Here, we take advantage of the properties of differentiated primary astrocytes in vitro to provide an insight into the mechanism underpinning astrocytic cell volume regulation and its correlation with the expression and function of AQP4, Transient Receptor Potential Vanilloid 4 (TRPV4), and Volume Regulated Anion Channel (VRAC). Methods: The calcein quenching method was used to study water transport and cell volume regulation. Calcium imaging and electrophysiology (patch-clamp) were used for functional analyses of calcium dynamics and chloride currents. Western blot and immunofluorescence were used to analyse the expression and localization of the channel proteins of interest. Results: We found that the increase in water permeability, previously observed in differentiated astrocytes, occurs simultaneously

M. G. Mola and E. Saracino contributed equally to this work.

\begin{tabular}{ll}
\hline Valentina Benfenati & Consiglio Nazionale delle Ricerche (CNR), Istituto per lo Sintesi Organica e la Fotoreattività (ISOF), \\
and Grazia Paola Nicchia & Via Gobetti 101, 40129 Bologna (Italy) \\
& Tel. +390516399786, E-Mail valentina.benfenati@isof.cnr.it
\end{tabular}




\section{Cellular Physiology Cell Physiol Biochem 2021;55(S1):196-212 \\ \begin{tabular}{ll|l} 
and Biochemisty & $\begin{array}{l}\text { DOI: } 10.33594 / 000000469 \\
\text { Published online: } 5 \text { November } 2021\end{array}$ & $\begin{array}{l}\text { c } 2021 \text { The Author(s). Published by } \\
\text { Cell Physiol Biochem Press GmbH\&Co. KG }\end{array}$
\end{tabular} \\ Mola et al.: Interplay of Chloride and Calcium Channels with Aquaporin-4 in Differentiated \\ Astrocytes}

with more efficient regulatory volume increase and regulatory volume decrease. Accordingly, the magnitude of the hypotonic induced intracellular calcium response, typically mediated by TRPV4, as well as the hypotonic induced VRAC current, was almost twice as high in differentiated astrocytes. Interestingly, while we confirmed increased AQP4 expression in the membrane of differentiated astrocytes, the expression of the channels TRPV4 and LeucineRich Repeats-Containing 8-A (LRRC8-A) were comparable between differentiated and nondifferentiated astrocytes. Conclusion: The reported results indicate that AQP4 up-regulation observed in differentiated astrocytes might promote higher sensitivity of the cell to osmotic changes, resulting in increased magnitude of calcium signaling and faster kinetics of the RVD and RVI processes. The implications for cell physiology and the mechanisms underlying astrocytic interaction with nanostructured interfaces are discussed.

(C) 2021 The Author(s). Published by Cell Physiol Biochem Press GmbH\&Co. KG

\section{Introduction}

Every cell is constantly challenged with osmolyte microgradient alterations as a result of metabolic cellular activity, nearby cell function and cell processes such as cell migration, proliferation, differentiation, signaling and apoptotic cell death. As a result, cell volume perturbation occurs both locally and globally [1-5]. Accordingly, the homeostasis of cell volume is efficiently preserved by processes referred to as Regulatory Volume Decrease (RVD) and Regulatory Volume Increase (RVI), driving the efflux or influx of ions and water for the cell to reach a new steady state.

A wealth of data indicates that astrocytes are essential for the maintenance of volume homeostasis in the brain since they are in charge of maintaining ions, water and osmolytes at their homeostatic concentrations [6-11]. In particular, astrocytes control ions and water dynamics at processes contacting synapses and siphon the excess of osmolytes and water to the blood vessels. Among protein channels involved in astrocytic regulation of the cell volume, the roles of water channel aquaporin-4 (AQP4), of calcium channels (belonging to the family of Transient Receptor potential Vanilloid 4 (TRPV4)), and of chloride channels (Volume Regulated Anion channels (VRAC)) are particularly important [12-15]. AQP4 is selectively expressed in astrocytic endfeet that face blood vessels, and it mainly accounts for faster, hydrostatically and osmotically driven water transport and distribution in the brain $[16,17]$. TRPV4 is a polymodal sensor that can be gated by different stimuli, including thermal stress, cell volume and anisotonic challenge across the plasma membrane [18-23]. In the cortex, TRPV4 is expressed mainly on astrocytic membranes that face blood vessels. In astrocytes in vitro and in Müller cells in situ, TRPV4 mediates osmotically induced calcium signaling involved in the cell volume regulation mechanism [6]. The efflux of Chloride ( $\left.\mathrm{Cl}^{-}\right)$ and organic osmolytes (such as taurine, glutamate, and aspartate) through VRAC allows for the recovery of physiological cell volume during the RVD process [24-26]. Recent studies have identified the protein called LRRC8-A in the plasma membrane of primary cortical astrocytes and in situ at the perivascular interface with endothelial cells. Moreover, LRRC8-A protein expression is essential for proper VRAC mediated osmolyte release [27] and currents as well as for astrocytic RVD and is a key factor for astroglial volume homeostasis $[9,28]$.

Cooperation between different molecular players has also been reported in vitro. TRPV4 cooperates with AQP4 in RVD in astrocytes $[19,20]$, possibly by molecular partnerships that occur in specific domains in situ [19]. The VRAC and AQP4 functional interaction has been demonstrated in primary astrocytes [26]. Notably, the alteration in expression and function of AQP4, TRPV4 and VRAC is widely recognized as pathogenic in neurological conditions characterized by dysregulation of astrocytic homeostatic control of volume [25]. All this evidence highlights that uncovering the mechanisms of cell volume regulation in astrocytes is of great interest. However, major technical issues arise in the study of astroglial cell volume regulation that limit the knowledge acquired thus far on the mechanisms behind it. To reach the resolution required for studying dynamics of microdomains in two photon-imaging experiments in vivo, higher power exposure is required that can lead to phototoxicity [29]. On 


\section{Cellular Physiology Cell Physiol Biochem 2021;55(S1):196-212 \\ \begin{tabular}{ll|l} 
and Biochemistyy & $\begin{array}{l}\text { DOI: } 10.33594 / 000000469 \\
\text { Published online: } 5 \text { November } 2021\end{array}$ & $\begin{array}{l}\text { C } 2021 \text { The Author(s). Published by } \\
\text { Cell Physiol Biochem Press GmbH\&Co. KG }\end{array}$
\end{tabular} \\ Mola et al.: Interplay of Chloride and Calcium Channels with Aquaporin-4 in Differentiated \\ Astrocytes}

the other hand, a major pitfall in the study of astroglial membrane channels involved in volume homeostasis in vitro is that, in standard cell culture conditions, their expression pattern does not resemble that observed in vivo [30-32]. In this context, we have demonstrated that plating astrocytes on a nano-structured interface, called hydrotalcite (HTlc), is an efficient method to obtain differentiated astrocytes in vitro, in terms of morphology differentiation and both molecular and functional features $[33,34]$. In particular, HTlc astrocytes displayed highly branched morphology, accompanied with increased expression of Kir4.1 protein and conductance and overexpression of AQP4, that was paralleled with increased swellinginduced water permeability [32].

Given the peculiarity of this cell culture approach, which allows for the study of astrocytes in vitro in a way that recapitulates important features of astrocytes in vivo, we sought to study cell volume regulation mechanisms in these differentiated astrocytes. In particular, we aimed to investigate the functional and molecular roles of the increased AQP4 mediated-water permeability associated with astrocyte differentiation, on TRPV4 mediated $\mathrm{Ca}^{2+}$ dynamics and on VRAC conductance in the so-called RVD and RVI mechanisms.

We found that RVD and RVI were more efficient in differentiated astrocytes. Moreover, while the expression of AQP4 is increased in the cell membrane, the expression of VRAC and TRPV4 is not. Surprisingly, swelling induced calcium increase as well as volume regulated chloride conductance are higher in magnitude in differentiated astrocytes compared to polygonal ones. The results presented here indicate that differentiated astrocytes respond to exposure to anisosmotic conditions with larger cell volume changes and larger restorative effects because overexpression of AQP4 channels leads to larger volume changes that in turn activate the volume regulatory effector mechanisms. Collectively, these data confirmed that AQP4 expression is critical for VRAC and TRPV4 function [18-20] and support the hypothesis that AQP4 upregulation in the cell membrane might serve as a driver for improved sensing and effector mechanisms responsible for astrocytic involvement in RVD and RVI.

\section{Materials and Methods}

\section{Primary astrocyte culture preparation and plating}

Primary cultures of cortical astrocytes were isolated from brains of postnatal Wistar rats, as described in [35]. Cells were grown in cell culture flasks containing DMEM-GlutaMAX medium supplemented with $10 \%$ fetal bovine serum (FBS) and penicillin/streptomycin $(100 \mathrm{U} / \mathrm{mL}$ and $100 \mu \mathrm{g} / \mathrm{mL}$, respectively). Astrocytes were maintained for 3-4 weeks in culture, and the medium was changed twice per week. Microglia and oligodendrocyte contaminating cells were removed by gently shaking the flasks, when necessary. Glial fibrillary acidic protein (GFAP) immunolabeling demonstrated that cells were $>95 \%$ type- 1 cortical astrocytes $[5,31,35]$. Once confluent, astrocytes were detached using trypsin-EDTA $0.025 \%$ and replated as a single-cell suspension onto either Poly-D-lysine (PDL) or hydrotalcite (HTlc) -coated petri dishes or glass coverslips, depending on the need. HTlc films were prepared according to protocols described previously [32]. Experiments were performed 5 days after re-plating. Astrocytes were seeded at a high density for western blot and calcein quenching experiments $\left(10^{4} \mathrm{cells} / \mathrm{cm}^{2}\right)$. For immunofluorescence experiments, cells were plated at a low density $\left(2 \times 10^{3}\right.$ cells $\left./ \mathrm{cm}^{2}\right)$. All cell culture products were purchased from Euroclone (Milan, Italy).

\section{Antibodies and Dyes}

The following primary antibodies were used: rabbit anti-AQP4 (Cat: sc-20812; Santa Cruz, Biotechnology, Dallas, Texas, USA) dilution 1:500, mouse anti-GFAP (Cat: G3893; Sigma, Saint Louis, Missouri, USA) dilution 1:500, rabbit anti-TRPV4 (Cat: ACC-034; Jerusalem BioPark, Israel) dilution 1:200, rabbit anti-LRRC8A (generated by Twin Helix, [28]; Western blot $8 \mu \mathrm{g} / \mathrm{ml}$; immunofluorescence $0.8 \mu \mathrm{g} / \mathrm{ml}$ ). The following secondary antibodies were used at dilutions of 1:1000 for immunofluorescence: AlexaFluor 488-conjugated donkey anti-mouse IgG (Cat: A21202) and AlexaFluor 488-conjugated donkey anti-rabbit IgG (Cat: A21206), both purchased from Thermo Fisher Scientific, Waltham, Massachusetts, USA. The following secondary antibodies were used at dilutions of 1:5000 for Western blots: horseradish peroxidase 


\section{Cellular Physiology Cell Physiol Biochem 2021;55(S1):196-212

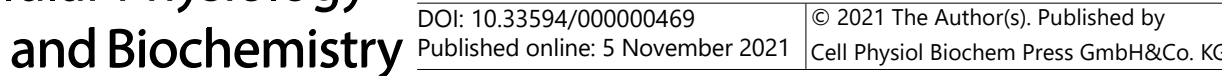 \\ Mola et al.: Interplay of Chloride and Calcium Channels with Aquaporin-4 in Differentiated \\ Astrocytes}

(HRP)-conjugated goat anti-rabbit IgG (sc-2004) and goat anti-mouse IgG (Cat: sc-2005), both purchased from Santa Cruz, Biotechnology, Dallas, Texas, USA. AlexaFluor 647-phalloidin (Cat: A22287) diluted 1:1000 was used to stain F-actin.

Protein sample preparation for SDS-PAGE, Western blotting and densitometric analysis

Astrocytes grown for 5 days on $60 \mathrm{~mm}$ petri dishes coated with either PDL or HTlc-films were washed once in ice-cold phosphate-buffered saline (PBS) and dissolved in five volumes of RIPA lysis buffer (10 mM Tris-HCl, pH 7.4, $140 \mathrm{mM} \mathrm{NaCl}, 1 \%$ Triton X-100, 1\% Na deoxycholate, $0.1 \%$ SDS, $1 \mathrm{mM} \mathrm{Na}_{3} \mathrm{VO}_{4^{\prime}}$ $1 \mathrm{mM} \mathrm{NaF}, 1 \mathrm{mM}$ EDTA and $1 \times$ Protease Inhibitor Cocktail). Cell lysis was performed on ice for $1 \mathrm{~h}$, and the samples were then centrifuged at $22,000 \mathrm{~g}$ for $30 \mathrm{~min}$ at $4^{\circ} \mathrm{C}$. Supernatants were collected and their protein content was measured using a bicinchoninic acid (BCA) Protein Assay Kit (Thermo Fisher Scientific, Waltham, Massachusetts, USA). 20 ug of membrane proteins/lane was dissolved in Laemmli Sample Buffer (Bio-Rad, Hercules, California, USA) and $50 \mathrm{mM}$ dithiothreitol, heated to $37^{\circ} \mathrm{C}$ for $10 \mathrm{~min}$, resolved on a $10 \%$ polyacrylamide gel, and transferred to polyvinylidene fluoride (PVDF) membranes (Merck Millipore, Burlington, Massachusetts, USA) for immunoblot analysis. Blocked membranes were incubated with primary antibodies, washed, then incubated with the appropriate peroxidase-conjugated IgG secondary antibodies. Reactive bands were revealed using enhanced chemiluminescence (Thermo Fisher Scientific, Waltham, Massachusetts, USA) and visualized on a Chemidoc imaging system (Bio-Rad, Hercules, California, USA). The density values of target bands were quantified with Image Lab software 5.2.1 and normalized to the Coomassie blue-stained membrane.

\section{Immunofluorescence and confocal microscopy analysis}

Cultured astrocytes grown on $12 \mathrm{~mm}$ diameter glass coverslips coated with PDL or HTlc were fixed in 4\% paraformaldehyde solution, rinsed 3 times in PBS (Euroclone, Milan, Italy) and permeabilized for 15 min with $0.3 \%$ Triton X-100 (Sigma, Saint Louis, Missouri, USA) in PBS. After blocking with 0.1\% gelatin (Sigma, Saint Louis, Missouri, USA) in PBS (blocking solution), cells were incubated for $1 \mathrm{~h}$ with primary antibodies, washed with blocking solution, and incubated for 45 min with the appropriate Alexa Fluor-conjugated secondary antibodies or AlexaFluor 647-phalloidin. Cover-slips were mounted on slides, using a medium containing 50\% Glycerol and $0.01 \%$ N-Propylgallate in PBS, and immunostained cells were observed with a confocal laser-scanning microscope (Leica TSC-SP8, Leica-Microsystems, Wetzlar, Germany). Single or wellspread cells were preferentially imaged for the analysis under 100X magnification. Fluorescence emission was obtained by laser excitation of Alexa Fluor 488 at $488 \mathrm{~nm}$ and for Alexa Fluor 647 at $640 \mathrm{~nm}$. Emission was collected between 510 and $540 \mathrm{~nm}$ and 670 to $720 \mathrm{~nm}$, respectively. Two empty areas with no cells in the field were also acquired and collected as sample background images for each condition. The auto contrast function was applied to the captured images as a whole using Adobe Photoshop CS6 software to improve the visual quality of images in terms of colour and contrast.

\section{Confocal microscopy analysis}

Image analysis was performed using Fiji software (NIH). After background subtraction, a minimum of three square-shaped ROIs with an area of $100 \mu \mathrm{m}^{2}$ was drawn at the edge of single and isolated astrocytes or on their processes, when expressed. The two-channel ROIs were analysed using the JACoP plug-in. The software defines an automatic threshold for each single-channel image and allows calculation of Pearson's coefficient $r$, which is a measure of correlation between actin (red channel) and membrane proteins (green channel). Pearson's coefficient values range from +1 to -1 , where +1 indicates a perfect positive relationship, -1 indicates a perfect negative relationship, and a 0 indicates no relationship. In this work, a high degree of correlation has been ascribed to the values lying between +0.50 and +1 , while coefficients lying between +0.1 and +0.49 have been interpreted as a moderate or poor degree of correlation. The results are the average of three independent experiments where 3 ROIs were analysed for each cell.

\section{Fluorescence-quenching Assay}

Cell-volume changes in primary cultured astrocytes were assessed using calcein-quenching fluorescence assay as described previously [35]. Astrocytes were seeded on black, clear-bottom, 96-well plates (Corning, New York, USA) coated with either PDL or HTlc at a density of 3,500 cells per well, and water permeability measurements were taken 5 days after plating. 


\section{Cellular Physiology Cell Physiol Biochem 2021;55(S1):196-212

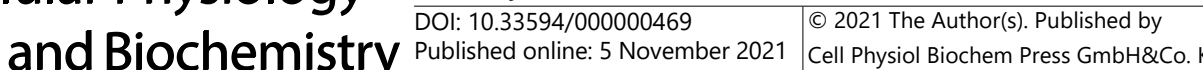 \\ Mola et al.: Interplay of Chloride and Calcium Channels with Aquaporin-4 in Differentiated Astrocytes}

Nearly 90\% confluent cells were loaded with $10 \mu \mathrm{M}$ membrane permeable calcein-AM (Molecular Probes, Eugene, Oregon, USA), which is trapped intra-cellularly after cleavage by esterases and exhibits a fluorescence intensity directly proportional to changes in cell volume. Calcein fluorescence kinetics in response to altered extracellular osmolarity were recorded on a FlexStation3 plate reader, equipped with a liquid handling module (Molecular Devices, San Jose, California, USA) able to transfer reagents from a source plate to the read plate during data acquisition. Fluorescence was excited at $490 \mathrm{~nm}$ and detected at $520 \mathrm{~nm}$ using dual monochromators.

Cells were rinsed in isotonic PBS, and the osmotic shift was applied by automated addition of an appropriate volume of hypotonic (NaCl-free PBS) or hypertonic (D-mannitol $0.5 \mathrm{M}$ ) solution in order to obtain the required final extracellular osmolarity [20, 35-39]. Calcein fluorescence intensity increased upon addition of hypotonic media due to water influx and cell swelling and decreased in response to hypertonic stimulation due to water efflux and cell shrinkage. Data acquisition was performed by SoftMax Pro software, and the data were analysed with Prism software (GraphPad Software, La Jolla, CA, USA).

The time constants of cell volume changes upon either the osmotic stimuli or regulatory volume decrease (RVD) were obtained by fitting the data with an exponential function. The time constant of the regulatory volume increase (RVI) kinetics registered after the hypertonic-induced cell shrinkage was calculated by the linear fitting of the tangent line to the initial region of the recovery curve and expressed as $1 /$ slope (s). The percentage of volume recovery was calculated from the maximum intensity of fluorescence reached after the osmotic shock (the amplitude of cell volume variation) and the level of fluorescence reached after the regulatory mechanism.

\section{Intracellular Calcium Measurements}

Intracellular calcium changes in response to hypotonic gradient were measured using the FlexStation3 plate reader, as previously described [20]. Astrocytes were seeded on black, clear-bottom, 96-well plates (Corning, New York, USA) coated with either PDL or HTlc at a density of 3,500 cells per well, and calcium measurements were done 5 days after plating. Cells were loaded with the ratiometric calcium indicator Fura-2-AM ( $8 \mu \mathrm{M}$; Molecular Probes, Eugene, Oregon, USA) in DMEM for $30 \mathrm{~min}$ at $37^{\circ} \mathrm{C}$. Cells were then washed with DPBS and stabilized in the same buffer for $10 \mathrm{~min}$ at $37^{\circ} \mathrm{C}$. The hypotonic stimulus was induced $20 \mathrm{~s}$ after the beginning of the data acquisition by adding an appropriate volume of hypotonic solution ( $\mathrm{NaCl}-$ free DPBS) in order to obtain the required final extracellular osmolarity, and the fluorescence was recorded for $100 \mathrm{~s}$. Intracellular calcium level was monitored by the ratio of the fluorescence intensity at $510 \mathrm{~nm}$ excited alternatively by $340 \mathrm{~nm}$ and $380 \mathrm{~nm}(\mathrm{~F} 340 / \mathrm{F} 380)$. The fluorescence ratio F340/F380 was used as an indicator of cytosolic $\left[\mathrm{Ca}^{2+}\right]$ changes, and the maximum intensity of F340/F380 ratio reached after the osmotic shock corresponds to the peak of calcium response. The relative time to reach this maximum was also measured. Data analysis was performed using SoftMaxPro and Prism 5 (Graph Pad).

\section{Electrophysiology}

Whole-cell recordings of swelling-activated $\mathrm{Cl}^{-}$currents were performed in cultured astrocytes as previously described [26]. Astrocytes plated both on PDL and HTlc were mounted on an inverted microscope (Nikon Diaphot; Nikon Italy, Firenze, Italy). Currents were recorded with the patch-clamp technique in a whole-cell configuration [40]. Patch pipettes were prepared from thin-walled borosilicate glass capillaries to obtain a tip resistance of 2-4 M $\Omega$. Membrane currents were amplified with an EPC-7 amplifier (List Electronic, Darmstadt, Germany) and low-pass filtered at $2 \mathrm{kHz}(3 \mathrm{~dB})$. Data were acquired with a sample rate of $5 \mathrm{kHz}$. Traces were analysed offline with pClamp 6 software (Axon Instrument, Foster City, CA, USA) and Origin 6.0 (MicroCal, Northampton, MA, USA). Experiments were performed at room temperature (22$\left.24^{\circ} \mathrm{C}\right)$.

Saline solutions for patch-clamp experiments were prepared with salts of the highest purity grade deionized and sterilized water (Millipore Sigma, Merck KGaA, Darmstadt, Germany). For electrophysiological recordings, the standard bath solution was the following (mM): $140 \mathrm{NaCl}, 4 \mathrm{KCl}, 2 \mathrm{MgCl}_{2}, 2 \mathrm{CaCl}_{2}, 10$ HEPES, 10 glucose, pH 7.4 adjusted with $\mathrm{NaOH}$, and the osmolarity was adjusted to $315 \mathrm{mOsm} / \mathrm{L}$ with mannitol. To isolate the $\mathrm{Cl}^{-}$current, the external bath perfusion, termed control saline, was the following (mM): $120 \mathrm{CsCl}, 2 \mathrm{MgCl}_{2}, 2 \mathrm{CaCl}_{2}, 10$ 2-[Tris (hydroxymethyl)-methylamino]-ethanesulfonic acid (TES), 10 glucose, $\mathrm{pH} 7.4$ adjusted with $\mathrm{CsOH}$, and the osmolarity was adjusted to $320 \mathrm{mOsm} / \mathrm{L}$ with mannitol $(60 \mathrm{mM})$. The intracellular (pipette) solution consisted of the following (mM): $126 \mathrm{CsCl}, 2 \mathrm{MgCl}_{2}, 1 \mathrm{EGTA}$, 


\section{Cellular Physiology Cell Physiol Biochem 2021;55(S1):196-212 \\ \begin{tabular}{ll|l} 
and Biochemistry & $\begin{array}{l}\text { DOl: } 10.33594 / 000000469 \\
\text { Published online: } 5 \text { November } 2021\end{array}$ & $\begin{array}{l}\text { C } 2021 \text { The Author(s). Published by } \\
\text { Cell Physiol Biochem Press GmbH\&Co. KG }\end{array}$
\end{tabular} \\ Mola et al.: Interplay of Chloride and Calcium Channels with Aquaporin-4 in Differentiated \\ Astrocytes}

10 TES, pH 7.2 adjusted with $\mathrm{CsOH}$, and the osmolarity was adjusted to $300 \mathrm{mOsm} / \mathrm{L}$ with mannitol. The hypotonic extracellular solution of $260 \mathrm{mOsm} / \mathrm{L}$ was obtained by omitting mannitol in the control solution. To block VRAC currents selectively, carbenoxolone (CBX) was freshly added to the hypotonic solution at a concentration of $100 \mu \mathrm{M}$ [41].

\section{Statistical analysis}

Three independent experiments were performed on different astrocyte primary culture preparations for quantitative analysis. Statistically significant differences between PDL and HTlc astrocyte cultures exposed to a range of osmotic gradients were computed using one-way ANOVA analysis with a subsequent Newman-Keuls Multiple Comparison Test. Shapiro-Wilk normality test was performed on Pearson's correlation coefficients; then statistical significance between conditions per channel was evaluated using the unpaired t-test. Data are shown as mean \pm SEM by using GraphPad Prism 5 software, and the level of significance was set at $\mathrm{p}<0.01$.

\section{Results}

HTlc astrocytes displayed faster cell volume changes and higher efficiency of cell volume regulation compared to PDL astrocytes

The availability of a reliable in vivo-like model of astrocytes [32] allowed us to study the AQP4-mediated water transport considering the well-known molecular up-regulation of this channel promoted by the HTlc interface. Measurements were made on primary cultures of rat astrocytes 5 days after re-plating on poly-D-Lysine (PDL) or HTlc.

The impact of HTlc nanoparticles on osmotically induced changes in cell volume was characterized by calcein quenching-based assay [32,35]. The osmotic behaviour of astrocytes grown on HTlc with respect to those grown on PDL was compared for their responsiveness in both hypotonic and hypertonic conditions. We also evaluated the dependence of water permeability parameters on the osmotic pressure gradient. Fig. 1A and B show representative data for the time courses of cell swelling in response to a series of hypotonic gradients between 20 and $100 \mathrm{mOsm} / \mathrm{L}$ recorded in PDL and HTlc plated astrocytes, respectively. Each shown kinetic includes a swelling phase related to the osmotic water influx and a regulatory volume phase that reached a steady-state cell volume (RVD phase). The time course of fluorescence signal was analysed in terms of swelling and RVD rate, swelling magnitude and percentage of volume recovery and measured parameters were compared between cells grown on PDL and HTlc substrates.

The analysis of the swelling phase revealed that HTlc astrocytes exhibited faster osmotic swelling compared to PDL astrocytes and that the measured swelling rate values were independent of the extracellular osmolarity in both growing substrates, as expected (Fig. 1C) [35, 42]. In agreement with previous studies [20, 37, 42, 43], we found a linear dependence of calcein signal $\left(\Delta \mathrm{F} / \mathrm{F}_{0}\right)$ on the relative change in cell volume in the whole range of osmotic gradients tested on both PDL and HTlc substrates (Supplementary Fig. S1A for all supplementary material see www.cellphysiolbiochem.com). Interestingly, astrocytes plated on HTlc films showed a significantly higher maximal amplitude of cell swelling for all osmotic gradient size compared to PDL astrocytes (Fig. 1D). Looking at the RVD phase, a higher efficiency of cell volume regulation in terms of rate of recovery (Fig. 1E) was detected in differentiated astrocytes in all hypotonic challenges. Similar to the trend observed in the swelling phase, the rate of the RVD phase was insensitive to the size of the osmotic gradient in both growing substrates. However, the percentage of volume recovery (Fig. 1F) was significantly enhanced at low osmotic gradients (20 and $25 \mathrm{mOsm} / \mathrm{L})$ in differentiated cells. In parallel, the impact of HTlc nanoparticles on the glial functional response to hypertonic shock was explored. Fig. 2A and B show representative time courses of cell shrinking in response to a range of hypertonic gradients between 20 and $100 \mathrm{mOsm} / \mathrm{L}$ recorded in PDL and HTlc plated astrocytes, respectively. Each shown kinetic response includes a shrinking phase triggered by the osmotic water efflux and a regulatory volume phase that tends to 


\section{Cellular Physiology Cell Physiol Biochem 2021;55(S1):196-212 \\ \begin{tabular}{ll|l} 
and Biochemistry $10.33594 / 000000469$ & C 2021 The Author(s). Published by \\
Published online: 5 November 2021 & Cell Physiol Biochem Press GmbH\&Co. KG
\end{tabular} \\ Mola et al.: Interplay of Chloride and Calcium Channels with Aquaporin-4 in Differentiated \\ Astrocytes}

Fig. 1. Comparison between water transport properties of PDL and HTlc plated astrocytes under hypotonic conditions. a, b) Representative time courses of cell swelling (swelling phase) followed by RVD kinetic (RVD phase) recorded from calcein-AM loaded PDL (a) and HTlc (b) astrocytes. The time course shows changes in fluorescence (F, expressed in arbitrary units, RFU) over time (s) induced by the indicated hypotonic gradients applied. The arrows indicate the switch in the external osmolarity. c, d) Quantitative analysis of the cell swelling time constants $(\tau)$ and of the swelling amplitude (in RFU) in astrocytes plated on PDL (white bars) and HTlc (gray bars) for each gradient size $(20,25,60,100$ in mOsm/L). e, f) Quantitative analysis of values of the time constants (e) and of the extent of volume recovery (\%) of the RVD phase (f) at the indicated hypotonic gradients. Note that AQP4 upregulation promotes faster swelling and RVD kinetics and higher efficiency of RVD. Data were obtained from 20 to 24 different measurements of three independent experiments performed using different astrocyte cultures. Significant differences of the means were calculated by One-way ANOVA and Newman-Keuls Mul-

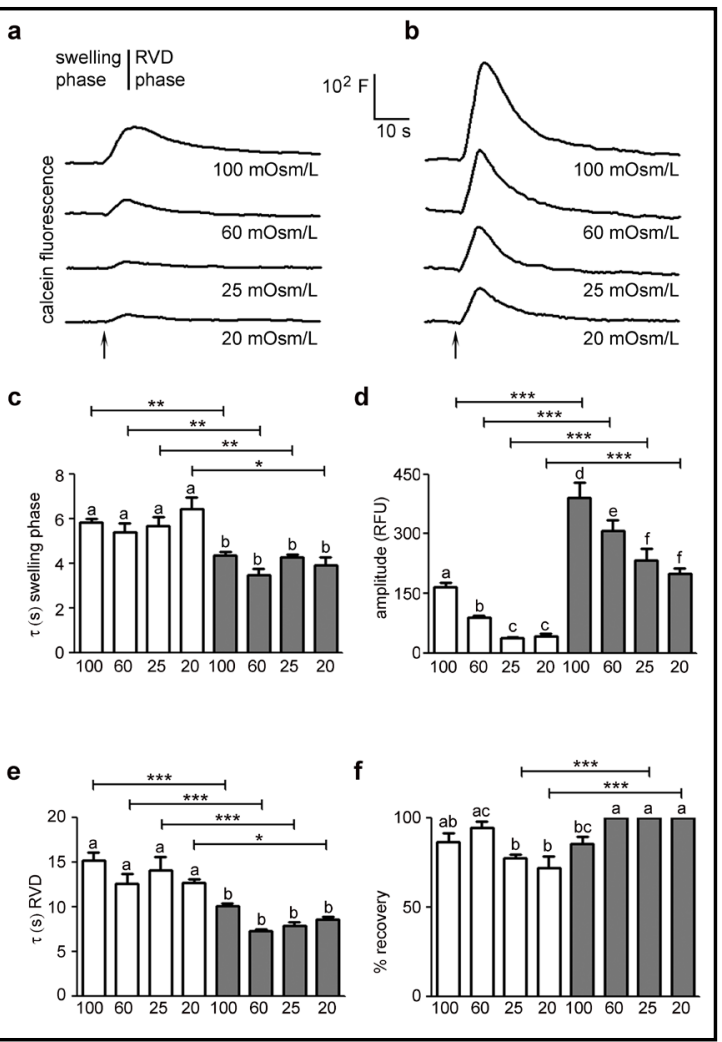
tiple Comparison Test. ${ }^{* * *} \mathrm{P}<0.0001 ;{ }^{* *} \mathrm{P}<0.001$; $* \mathrm{P}<0.01$. Different letters on top of each bar indicate significant difference between them and equal letters indicate no significant difference.

restore cell volume (RVI phase). The cell shrinking rates, computed from the time course data, were found to be remarkably enhanced in HTlc astrocytes compared to PDL astrocytes. Again, both PDL and HTlc astrocytes were insensitive to the entity of the osmotic shock (Fig. 2C). As observed in hypotonic conditions, the maximal amplitude of cell shrinkage was enhanced in differentiated astrocytes (Fig. 2D) and linearly related to the extracellular buffer osmolarity both in HTlc and PDL astrocytes (Supplementary Fig. S1B). Finally, HTlc films also promoted RVI efficiency in terms of rate (Fig. 2E) and extent of volume recovery at all hypertonic osmolarities in HTlc compared to PDL plated astrocytes (Fig. 2F). Similar to the RVD, the RVI response was also independent of the extracellular osmolarity in both differentiated and undifferentiated cells.

Swelling-induced calcium and chloride current response was up-regulated in astrocytes grown on HTlc nanoparticles

The osmotic swelling of cultured astrocytes in response to hypotonic stress has been associated with a transient rise in cytosolic calcium $[19,20]$. Here, we used HTlcdifferentiated astrocytes to evaluate whether faster cell swelling and higher volume increase observed in HTLc cells could have an effect on hypotonicity induced calcium influx (Fig. $3 \mathrm{~A}$ and $\mathrm{B}$ ). To this end we exposed astrocytes plated on PDL and HTlc plated astrocytes to hypotonic challenge $(0 \mathrm{sm}=60 \mathrm{mOsm} / \mathrm{L})$ at room temperature, a condition essential to distinguish the response of TRPV4 to diverse modalities of activation [44]. Notably, the hypotonic challenge induces comparable calcium increase in PDL and HTlc (Fig. 3A, B). The role of TRPV4 in hypotonic induced calcium signaling in astrocytes was evaluated by adding

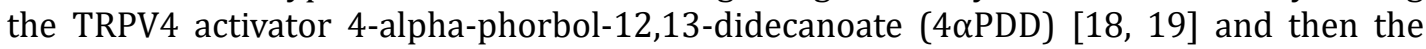
TRPV4 antagonist RN1734 to the hypotonic solution $[45,46]$. We demonstrate that both PDL and HTlc astrocytes respond to the addition of TRPV4 agonist $4 \alpha$ PDD to the hypotonic 


\section{Cellular Physiology Cell Physiol Biochem 2021;55(S1):196-212

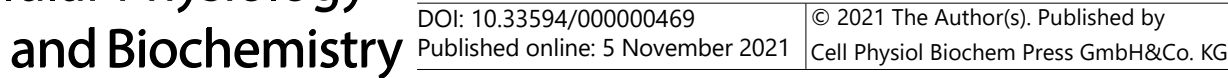 \\ Mola et al.: Interplay of Chloride and Calcium Channels with Aquaporin-4 in Differentiated Astrocytes}

Fig. 2. Comparison of water transport properties of PDL and HTlc plated astrocytes under hypertonic conditions. a, b) Representative time courses of calcein-AM loaded cells during the shrinking phase followed by RVI kinetic (RVI phase) recorded on PDL (a) and HTlc (b) substrates and showing changes in fluorescence signal $(F$, expressed in arbitrary units, RFU) elicited by hypertonic stimulations, as indicated. The arrows indicate the switch in the external osmolarity. c, d) Quantitative analysis of the cell shrinking time constants $(\tau)$ and of the shrinking amplitude (in RFU) measured in astrocytes plated on PDL (white bars) and HTlc (gray bars) for each gradient size $(20,25,60,100$ in $\mathrm{mOsm} / \mathrm{L}$ ). e, f) Quantitative analysis of the rate of the RVI phase (1/slope, s) (e) and of the extent of volume recovery (\%) (f) at the applied hypertonic gradients. Note that AQP4 upregulation promotes faster shrinking and RVI kinetics and higher efficiency of RVI. Data were obtained from 21 to 24 different measurements of three independent experiments performed using different astrocyte cultures. A One-way Anova and Newman-Keuls Multiple Comparison Test were performed. ${ }^{* * *} \mathrm{P}<0.0001$; ${ }^{* *} \mathrm{P}<0.001 ;{ }^{*} \mathrm{P}<0.01$. Different letters on top of each bar indicate significant difference between them

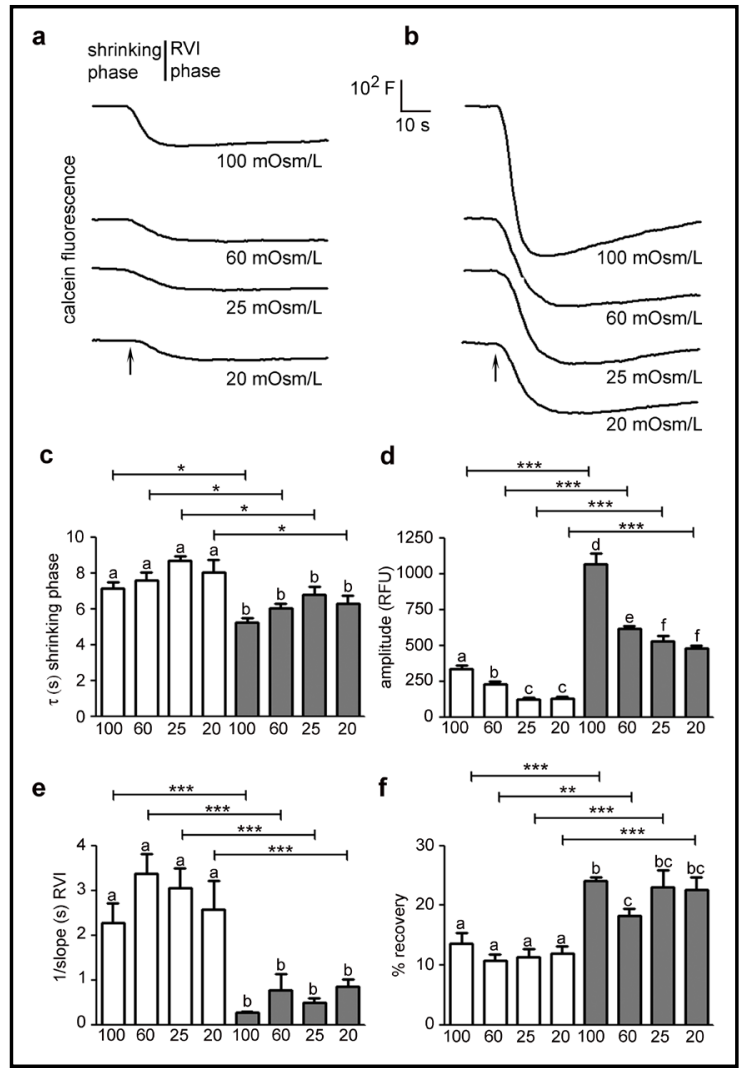
and equal letters indicate no significant difference.

solution with an increase in intracellular calcium signaling. Notably, the magnitude of the increase in calcium response, observed after application of the agonist $4 \alpha \mathrm{PDD}$ to hypotonic solution, was significantly higher in HTlc-differentiated cells compared to PDL cells (Fig. $3 \mathrm{~A}, \mathrm{~B})$. Accordingly, the increase induced by the TRPV4 agonist is significantly reduced after sequential addition of TRPV4 antagonist RN1734. Next, we studied intracellular calcium variations induced by hypotonic challenge at a physiological temperature of $37^{\circ} \mathrm{C}$, at which TRPV4 is constitutively activated in heterologous system and in cortical astrocytes in situ $[21,45]$. We found that hypotonicity induced calcium increase was higher in amplitude in HTlc differentiated astrocytes than in PDL astrocytes at all the hypotonic gradients tested between 20 and $100 \mathrm{mOsm} / \mathrm{L}$. The magnitude of the response increases proportionally with osmotic challenge. On the other hand, the time-to-peak values remained unaffected (Supplementary Fig. S2).

To analyze hypotonicity-activated current, we applied protocols previously reported $[26,28]$. Accordingly, astrocytes were clamped at the holding potential (Vh) of $0 \mathrm{mV}$, next to the astrocyte zero-current potential under our experimental conditions, and stimulated with voltage ramps of 1-s duration from -80 to $80 \mathrm{mV}$ (Fig. 4A, B). Whole-cell membrane conductance recorded in extracellular isotonic saline (Fig. 4A, trace 1) was small in magnitude and increased upon exposure to hypotonic solution $(\Delta 0 \mathrm{sm}=60 \mathrm{mOsm})$ in PDL astrocytes [46], (Fig. 4A, trace 2). Of note, steady-state ramp currents were inhibited by a micromolar concentration of VRAC inhibitor carbenoxolone (Fig. 4A, trace 3) [39]. In HTlc plated astrocytes, hypotonic challenge proved to elicit a significant increase in the magnitude of whole-cell currents compared to PDL plated astrocytes (Fig. 4B, E). 
Mola et al.: Interplay of Chloride and Calcium Channels with Aquaporin-4 in Differentiated Astrocytes

Fig. 3. Hypotonicity-induced calcium increase in PDL and HTlc differentiated astrocytes. a) Representative trace of hypotonicityinduced $\mathrm{Ca}^{2+}$ response recorded from cells grown on PDL and HTlc films observed after exposing the cells to hypotonic solution $(\Delta \mathrm{Osm}=$ $60 \mathrm{mOsm} / \mathrm{L}$, lane 1) or to hypotonic solution with TRPV4 agonist $4 \alpha$ PDD or with $4 \alpha$ PDD +TRPV4 antagonist RN1734. The arrows indicate the time at which solutions were added to the control saline. Experiments were performed at RT. b) Barplot showing the

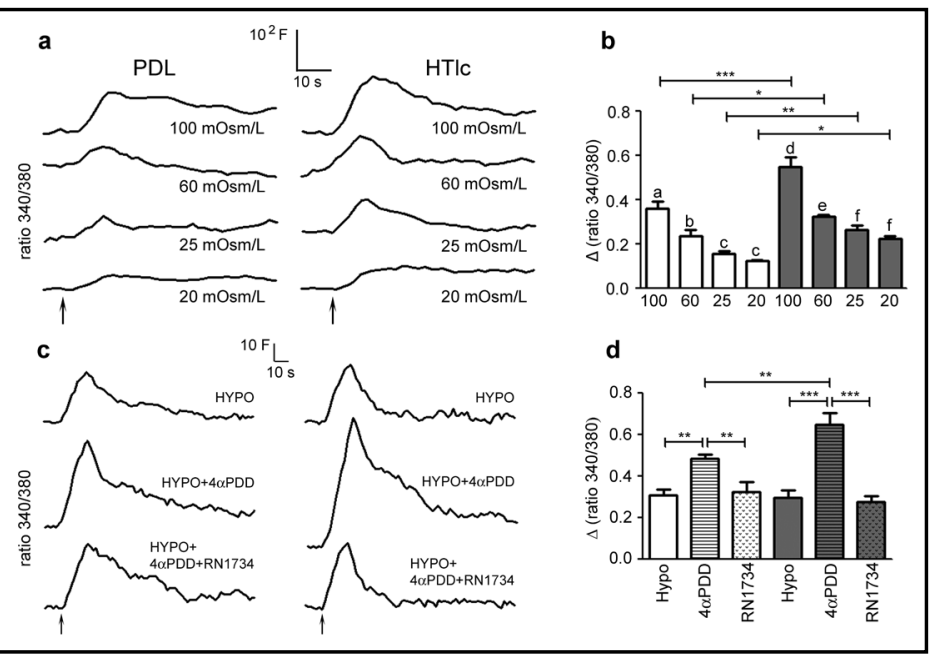
mean \pm SE values of the increased $\mathrm{Ca}^{2+}$ amplitudes measured in the conditions reported in A. Data were obtained from 12 to 15 different measurements of three independent experiments performed using 3 different astrocyte cultures. One-way ANOVA and Newman-Keuls Multiple Comparison Tests were performed. ${ }^{* *}{ }^{*} \mathrm{P}<0.0001 ;{ }^{* *} \mathrm{P}<0.001 ;{ }^{*} \mathrm{P}<0.01$. c) Representative traces reflecting variations of cytosolic calcium $\mathrm{Ca}^{2+}$ concentration recorded in cells grown on PDL and on HTlc films. Experiments were performed at $37^{\circ} \mathrm{C}$. The osmotic challenges were obtained by addition of NaCl-free PBS in order to apply the indicated osmotic gradient size, at the timepoint indicated by the arrow. d) Bar plot showing the mean \pm SE values of calcium variations measured in the conditions reported in c. Data were obtained from 20 to 24 different measurements of three independent experiments performed using different astrocyte cultures. One-way ANOVA and Newman-Keuls Multiple Comparison Tests were performed. ${ }^{* * *} \mathrm{P}<0.0001 ;{ }^{* *} \mathrm{P}<0.001 ;{ }^{*} \mathrm{P}<0.01$.

Fig. 4. VRAC-mediated current in astrocytes plated on PDL and HTlc. Representative current traces recorded in astrocytes plated on PDL (a) and HTlc (b) in response to ramp current protocol (inset). The reported current traces were recorded in isotonic solution (trace 1), at the maximal amplitude observed after exposure to the hypotonic solution (trace 2, $\Delta=60 \mathrm{mOsm} / \mathrm{L}$ ), and after addition

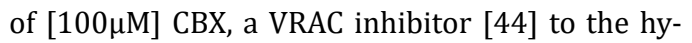
potonic solution (trace 3). Dashed lines represent the zero-current value. c,d) Representative current traces of hypotonic-challenge-activated current recorded in astrocytes plated on PDL (c) and HTlc (d) in response to family of voltage steps protocol (inset). Astrocytes were voltage clamped at the holding potential (Vh) of $0 \mathrm{mV}$, and families of voltage steps of $20 \mathrm{mV}$ increments were delivered from -80 $\mathrm{mV}$ to $+80 \mathrm{mV}$, every $10 \mathrm{sec}$. Hypotonic-challengeactivated current traces were obtained by digital subtraction of the steady-state current, recorded in isotonic condition, from the maximal value of

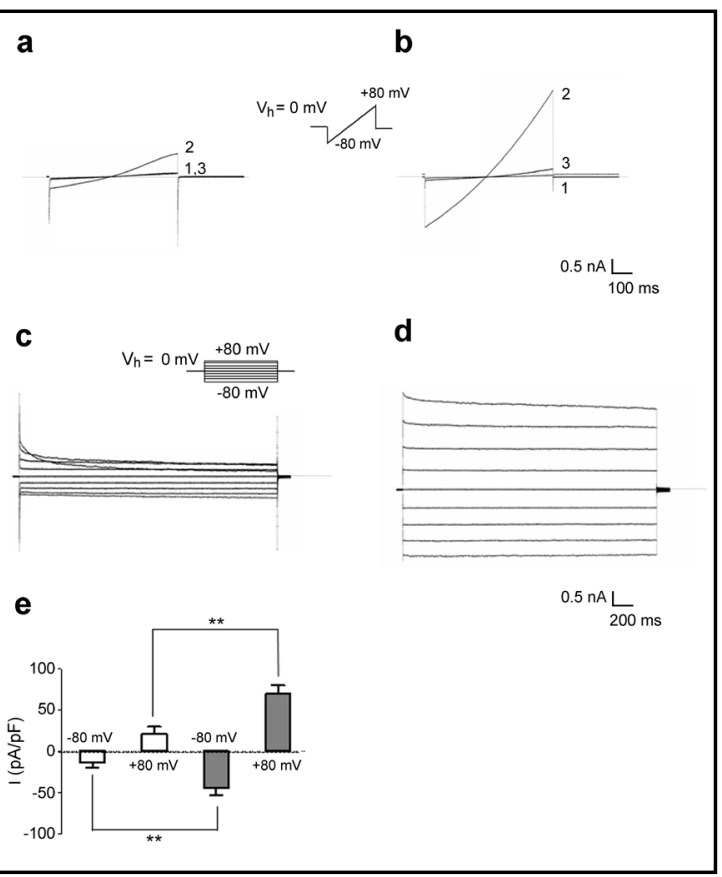
current amplitude, recorded after exposure of the cell to hypotonic saline ( $\Delta=60 \mathrm{mOsm} / \mathrm{L})$. e) Bar plot of maximal hypotonicity-activated current densities recorded at -80 and $+80 \mathrm{mV}$ in PDL (white bars) and HTlc plated astrocytes (gray bars). Data are expressed as mean $\pm \operatorname{SE}\left(n=6 ;{ }^{* *} \mathrm{p}<0.01\right.$, with Student's t test $)$. 


\section{Cellular Physiology Cell Physiol Biochem 2021;55(S1):196-212 \\ \begin{tabular}{ll|l} 
and Biochemistry & DOl: 10.33594/000000469 & O 2021 The Author(s). Published by \\
\cline { 2 - 3 } Published online: 5 November 2021 & Cell Physiol Biochem Press GmbH\&Co. KG
\end{tabular} \\ Mola et al.: Interplay of Chloride and Calcium Channels with Aquaporin-4 in Differentiated \\ Astrocytes}

In order to analyze whether HTlc plating affects biophysical properties of VRAC, the voltage- and time-dependency of VRAC was analyzed in PDL (Fig. 4C) and in HTlc (Fig. 4D) plated astrocytes. To this end, $\mathrm{Cl}^{-}$currents were elicited with a voltage step protocol (Fig. $4 \mathrm{C}$, inset), consisting of a family of voltage steps from $\mathrm{Vh} 0 \mathrm{mV}$ from -80 to $+80 \mathrm{mV}$ in $20 \mathrm{mV}$ increments delivered every $10 \mathrm{sec}$.

Hypotonicity-activated currents were obtained by digital subtraction of current traces recorded after 5-7 min of exposure to hypotonic saline from the currents recorded in control saline (Fig. 4C). Consistently with the VRAC biophysical profile, the currents in HTlc astrocytes activated instantaneously at all voltages and did not inactivate at potentials between -40 and $+40 \mathrm{mV}$ (Fig. 4D). At membrane potentials higher than $+40 \mathrm{mV}$, the hypotonicity-evoked currents displayed a typical time-dependent inactivation, the rate and extent of which became larger at more depolarized potentials.

The expression levels of TRPV4 and VRAC channels are not altered in HTlc differentiated astrocytes

In line with our previous results, GFAP staining (Fig. 5A) revealed a polygonal shape in astrocytes grown on PDL and a remarkable morphological differentiation in HTlc plated astrocytes. Immunoblotting analysis confirmed comparable expression levels of GFAP, a wellknown gliotic inflammatory marker (Fig. 5B and C) in cells grown on both substrates as well as the molecular up-regulation of AQP4 in HTlc-plated astrocytes. On the other hand, TRPV4 and VRAC protein expression levels remained unaltered in cells grown on HTlc compared to those grown on PDL.

To assess whether a gain in functionality was associated with a different expression pattern of the channels in the membrane, fixed astrocytes labelled for F-actin and the three aforementioned proteins were imaged using confocal microscopy (Fig. 6). The F-actin label was chosen in order to easily discriminate between differentiated and undifferentiated astrocytes as well as to identify the median focal planes within the cells with well-defined cell edges. Pearson's coefficients obtained from co-localization analysis between the membrane channels and F-actin showed that, while TRPV4 and VRAC were similarly distributed in both differentiated and undifferentiated cells without correlation to the F-actin distribution, AQP4 localization exhibited a profound rearrangement in differentiated star-shaped astrocytes grown on HTlc with a continuous plasma membrane staining strongly colocalized with cortical actin.

Fig. 5. Expression of GFAP, AQP4, TRPV4 and LRRC8-A proteins in astrocytes plated on PDL and HTlc. a) GFAP staining of PDL and HTlc astrocytes. (Scale bar: $50 \mu \mathrm{m}$ ). b) Representative Western blot analysis of GFAP, AQP4, TRPV4 and LRRC8-A expression in primary astrocytes grown on PDL and HTlc. c) Comparative densitometric analysis of GFAP, AQP4, TRPV4 and LRRC8-A corresponding signal in PDL and HTlc samples, normalized to the Coomassie blue-stained membrane. Data are means $\pm S E$, $* * * \mathrm{p}<0.001$.

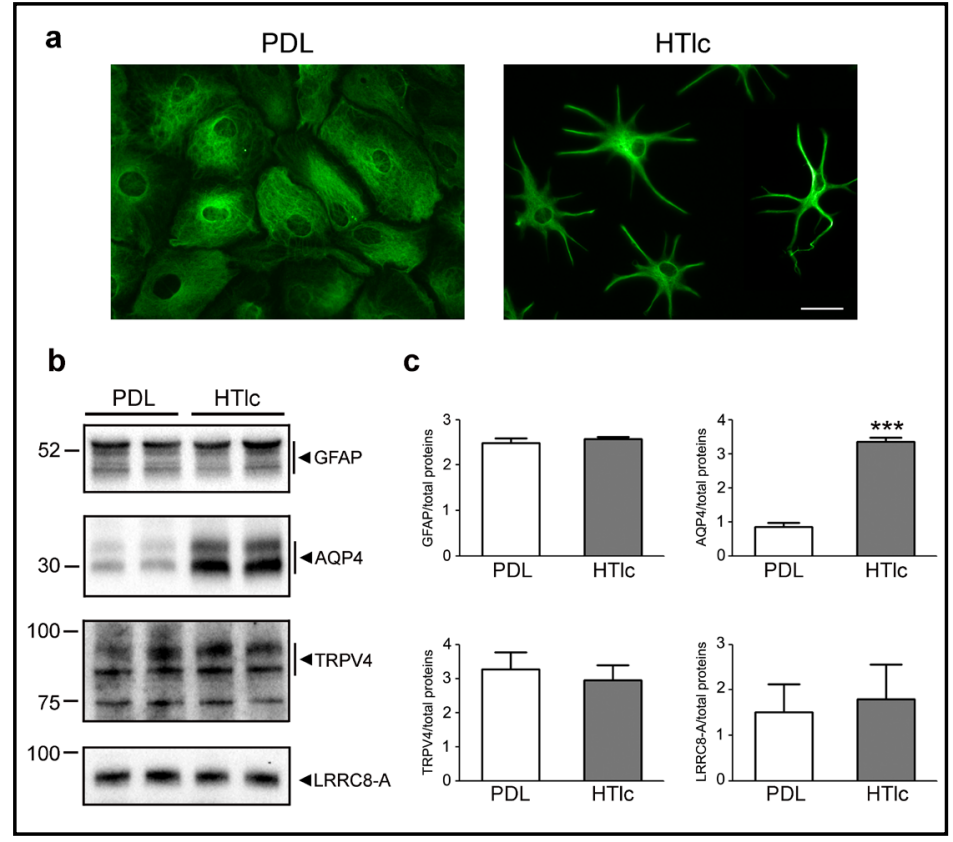


Mola et al.: Interplay of Chloride and Calcium Channels with Aquaporin-4 in Differentiated Astrocytes

Fig. 6. AQP4, VRAC and TRPV4 protein expression and localization. a) Single-plane confocal images of astrocytes grown on PDL (upper panel) and HTlc (lower panel) immunostained for the channels (green) and F-actin (red) (Scale bar: $25 \mathrm{um}$ ). b) Magnification of the yellow-boxed regions from (a) (insets: 10 um x 10 um). c) Pearson's Correlation Coefficients resulting from colocalization analysis between membrane proteins and F-actin. In HTlc-grown astrocytes, AQP4 and F-actin colocalize with a greater extent compared to undifferentiated cells/ controls (Pearson's coefficient $(r)=0.65 \pm 0.01, n=27$ for HTlc; $r=0.21 \pm 0.02, n=45$ for PDL). No changes in the degree of overlap between VRAC or TRPV4 and Factin were detected in differentiated astrocytes ( $\mathrm{r}$ VRAC HTlc $=0.382$ $\pm 0.03, \mathrm{n}=45 ; \mathrm{r}$ VRAC PDL $=0.31$ $\pm 0.02, \mathrm{n}=45 ; \mathrm{r}$ TRPV4 HTlc $=0.229$ $\pm 0.03, \mathrm{n}=48 ; \mathrm{r}$ TRPV4 PDL $=0.24$
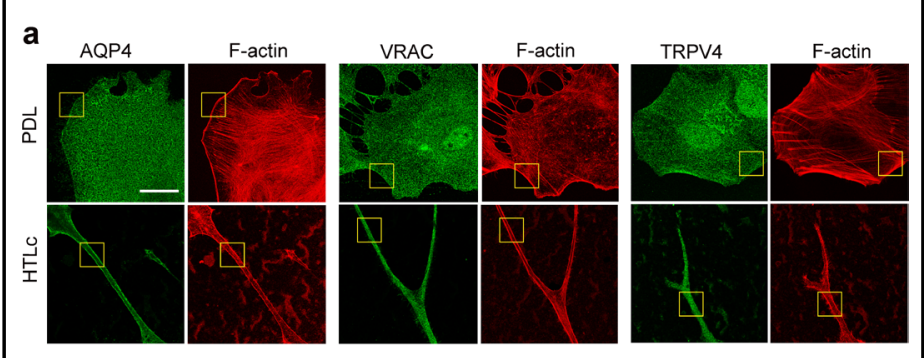

b AQP4
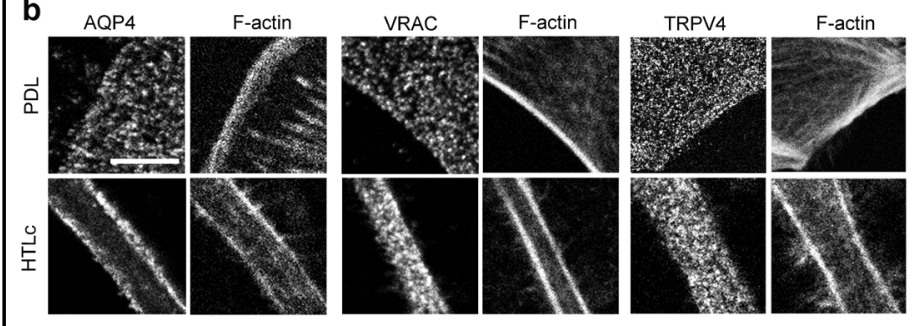

C

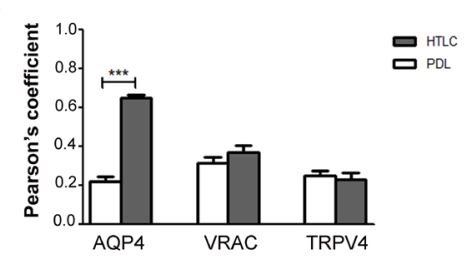

$\pm 0.02, \mathrm{n}=45$ ). Unpaired t-test;

$* * * \mathrm{P} \leq 0.0001$.

\section{Discussion}

Several studies highlight that the astroglial syncytium strategically regulates homeostasis within the brain environment through a pool of ion and water channel proteins specifically distributed in microdomains facing diverse fluid-filled spaces [1,47]. Astrocytic cell volume regulation in response to anisotonicity results from 1) sensing anisotonic environment and cell volume changes caused by osmotically driven water flux across the cell membrane; and 2) activation of effector mechanisms that restore the original cell volume. However, the mechanism behind cell volume regulation needs further insights.

In this work, we sought to investigate cell volume regulating mechanisms in differentiated astrocytes in vitro [32], that recapitulate morphological, molecular and functional features of astrocytes in situ. We confirm that AQP4-overexpression is accompanied with enhanced rate of water transport in astrocytes under hypotonic conditions and, as herein demonstrated, also under hypertonic conditions. Notably, the amplitude of the anisotonicity-induced cell volume responses of glial cells were considerably higher in differentiated astrocytes. One of the major novel findings of the present work is the improved response of differentiated astrocytes in terms of volume recovery.

To obtain insight into this phenomenon, we studied the hypotonicity induced calcium signalling and volume regulated anion conductance in PDL and HTlc astrocytes because they are mainly responsible for the cell sensing and effector mechanisms activated by anisotonicity.

We found that hypotonicity induced calcium signals is increased in its magnitude in differentiated astrocytes only when TRPV4 is activated by the selective agonist (Fig. 4A, B) or by temperature above $25^{\circ} \mathrm{C}$. Thus, the upregulation might be either dependent or independent of the higher swelling observed in experiments performed at $22^{\circ} \mathrm{C}$. 


\section{Cellular Physiology Cell Physiol Biochem 2021;55(S1):196-212 \\ \begin{tabular}{ll|l} 
DOl: 10.33594/000000469 & O 2021 The Author(s). Published by \\
Cell Physiol Biochem Press GmbH\&Co. KG
\end{tabular} \\ Mola et al.: Interplay of Chloride and Calcium Channels with Aquaporin-4 in Differentiated \\ Astrocytes}

Notably, the amplitude of the swelling kinetics was half as large as the amplitude of shrinking kinetics [48]. Cell swelling processes are more complex than cell shrinkage as the plasma membrane exhibits a very limited stretch capacity and is constrained by extensive cytoskeletal networks [10].

Astrocytes grown on HTlc films display faster active RVD and RVI together with a more efficient volume recovery compared to undifferentiated cells.

It can be argued that the different surface-to-volume ratio between flat and stellate astrocytes should be taken into account with respect to the increased water transport kinetic properties measured in cells grown on HTlc. However, in line with previous manuscripts published by our group in which a morphological change of astrocytes was obtained, [31, 32, $49,50]$ we have considered here the time constant of cell swelling or cell shrinkage a sufficient indicator of the water flux rate. In general, we have demonstrated that cell differentiation promotes the polarized expression of AQP4 on the cell plasma membrane associated with an increased water transport rate, suggesting that the selective AQP4 plasma membrane localization positively affects the permeability and the cell volume recovery mechanism in differentiated astrocytes.

It is plausible that AQP4 dependent increases in the plasma membrane stretching abilities are able to drive higher sensitivity of the cell to osmotic changes, thereby resulting in increased magnitude of osmotic induced calcium signaling (Fig. 3A and B) and faster kinetics of the RVD and RVI processes. Accordingly, we previously demonstrated [19, 20] that the hypotonicity-induced calcium transients recorded from WT and KO astrocytes were significantly different in terms of amplitudes and kinetics, indicating that the more rapid cell swelling provided by AQP4-mediated water influx plays a major modulatory role on TRPV4mediated calcium signalling events.

Recent works have also indicated that TRPV4 is more of a volume-sensor than an osmo-sensor [51]. The results provided at room temperature are, however, more in favor of the ability of TRPV4 increased magnitude to sense osmolarity more than the cell volume. Indeed, increased magnitude of calcium signal in HTLc is observed only when TRPV4 is already activated by temperature or by an agonist, two conditions where discrimination among stimuli cannot be achieved $[44,52]$. Our results support the tenet that AQP4 is a crucial player in the RVD and RVI mechanisms and that a molecular and functional interaction with TRPV4 exists in differentiated astrocytes [19, 20, 33, 53]. Our results have also demonstrated a dramatic increase in VRAC current in response to hypotonic challenge in differentiated astrocytes. The result observed might explain the more efficient kinetics of RVD observed in these cells following rapid osmotic influx or efflux of water in response to an anisotonic stimulus. The result is not surprising since, indeed, VRAC channels are known to be critical contributors to the cell volume regulation in astrocytes [27, 28, 34]. Moreover, in a previous work we found that AQP4-KD induced a down regulation of VRAC current [26]. Thus, a functional cooperation between AQP4 mediated swelling and VRAC is confirmed in differentiated astrocytes. We recently found that the expression of LRRC8A subunit of VRAC was essential for the amplitude of astrocytic VRAC conductance and RVD. However, in the present work, the increase in magnitude of VRAC current was not paralleled by an increase in LRRC8A total protein amount nor by higher expression in the astrocytic membrane. Thus, it is plausible that, in the case of VRAC, the higher cell volume achieved is linked to the higher expression of AQP4 in the cell membrane, resulting in a more effective stimulus for the activation of VRAC.

\section{Cell volume regulation nanostructure induced differentiation}

The herein reported nano-scale interface, HTlc, is known to promote differentiation of astrocytes with mechanisms involving the cytoskeleton rearrangement $[32,55,56]$. The tight interaction of the cell with the nano-scale environment might continuously challenge the cell, locally, to rearrange its surface and volume. Thus, RVD and RVI molecular and functional components could be improved. In this regard, a prominent role for RVD and AQP4 in glioma cells has been highlighted $[57,58]$. The latter condition is typically characterized by 


\section{Cellular Physiology Cell Physiol Biochem 2021;55(S1):196-212 \\ \begin{tabular}{ll|l} 
DOl: 10.33594/000000469 & O 2021 The Author(s). Published by \\
Cell Physiol Biochem Press GmbH\&Co. KG
\end{tabular} \\ Mola et al.: Interplay of Chloride and Calcium Channels with Aquaporin-4 in Differentiated \\ Astrocytes}

alterations in mechanical properties of the extracellular environment, and AQP4 mediated water flux seems to play a key role orienting glioma cell fate toward increased migration properties (AQP4 dependent increase in cell migration) or apoptosis (AQP4 dependent apoptotic volume decrease) [57]. In addition, it has been recently shown that TRPV4 might act as mechano-sensor in astrocytes. Thus, the increased response of TRPV4 in differentiated astrocytes might be a consequence of the nanomechanical challenge induced by HTlc. This, on turn, might set a lower threshold to activate TRPV4 in response to osmotic challenge or to cell volume. In this respect, the data herein provided and the growth of astrocytes on HTlc will be useful to understand the molecular mechanisms of differentiation and migration, as two typical traits of astrocytes in health and disease.

We can also speculate that the cell/material interface induces gene expression driving a molecular and functional phenotype that is more similar to the one observed in vivo, as previously described, which includes recapitulation of microdomains serving homeostatic function to which AQP4, Kir4.1 [32], TRPV4 and, more recently, VRAC have been demonstrated to belong $[26,28]$. In this view, our work provides new insight into cell physiology and biophysics by controlled in vivo-mimicking - in vitro cell culture model.

\section{Conclusion}

Here we demonstrate that the differentiation of astrocytes is associated with an increased AQP4 dependent water permeability. We hypothesized that the enhanced transmembrane osmotic water flux, conferred by the upregulated water channel protein and function, might drive higher sensitivity of the cell to osmotic changes. This enhanced flux results in increased magnitude of calcium signaling and faster kinetics of the RVD and RVI processes by functionally recruiting both TRPV4 and VRAC ion channels, even though the total protein levels of both TRPV4 and VRAC remain unaltered.

The present in vitro cell culture method to obtain differentiated astrocytes represents an important tool to study the dynamics underpinning the cellular localization and functionality of channel proteins belonging to astrocytic microdomains and has allowed us to test the hypothesis that volume transmission is a new communication path in non-excitable cells.

\section{Acknowledgements}

The authors would like to thank Alessia Minardi (University of Bologna) for assistance in the astrocyte preparation, Gaetano Devito (University of Bari) for his excellent technical assistance, and Kate O'Neill (University of Maryland) for her assistance in revising the English of the article.

\section{Author Contributions}

M.G. Mola designed and performed water transport experiments, wrote the paper. E. Saracino set the protocol for differentiated astrocytes, performed calcium imaging experiments, wrote the paper. F. Formaggio performed patch-clamp experiments, analyzed electrophysiology data, wrote the paper. A. G. Amerotti and A. Cibelli performed western blot experiments and analyses. B. Barile and C. Palazzo performed immunofluorescence and confocal microscopy. T. Posati synthetized HTlc films. A. Frigeri discussed the data, wrote and corrected the manuscript. R. Zamboni discussed the data and corrected the manuscript, M. Caprini discussed the data, designed electrophysiology experiments and wrote the paper. G. P. Nicchia and V. Benfenati designed and supervised the research, discussed the data, wrote the manuscript. 


\section{Cellular Physiology Cell Physiol Biochem 2021;55(S1):196-212 \begin{tabular}{l|l|l}
\hline DOI: 10.33594/000000469 2021 The Author(s). Published by \\
\hline
\end{tabular} and Biochemistry Published online: 5 November 2021 Cell Physiol Biochem Press GmbH\&Co. KG \\ Mola et al.: Interplay of Chloride and Calcium Channels with Aquaporin-4 in Differentiated Astrocytes}

\section{Funding Sources}

The work is supported by AFOSR Research Projects FA9550-19-1-0370: “Decoding astrocytes rhythm"; ASTROMAT: FA9550-16-1-0502; 3D NEUROGLIA: FA9550-18-1-0255; ASTRONIR: FA9550-17-1-0502; ASTROLIGHT: FA9550-20-1-0386; MSCA-ITN-2020ASTROTECH (GA956325); E.S. is supported by POR-FESR 2014-2020 of Emilia Romagna Region, Fondo per lo Sviluppo e la Coesione (MAT-2-REP-FSC), and Grant sponsor Italian Ministry of the University and Research-FIRB Futuro in Ricerca (RBFR12SJA8).

\section{Statement of Ethics}

Experiments were performed in accordance with the European guidelines on the ethical use of animals for research and the Italian law on animal care. The animal use protocol for this study was approved by the Institutional Committee on Animal Research and Ethics of the University of Bari and Bologna and by the Italian Ministry of Health (protocol number no. 2020/1338-PR, renewed on February 2020 and valid for 5 years). Wistar rats provided by Charles River were bred in the Animal Facilities of the Universities of Bari and Bologna, and the pups were used for brain explant and cell culture preparation. Rats were kept under a 12 -h dark to light cycle, at constant room temperature and humidity $\left(22 \pm 2{ }^{\circ} \mathrm{C}, 75 \%\right)$, with food and water ad libitum in 1290D Eurostandard Type III cages (Tecniplast, Varese, Italy). Experiments were designed to minimize the number of animals used and their suffering.

\section{Disclosure Statement}

The authors have no conflicts of interest to declare.

\section{References}

1 Benfenati V, Ferroni S: Water transport between CNS compartments: Functional and molecular interactions between aquaporins and ion channels. Neuroscience 2010;168:926-940.

2 Lang F, Busch GL, Ritter M, Völkl H, Waldegger S, Gulbins E, Häussinger D: Functional Significance of Cell Volume Regulatory Mechanisms. Physiol Rev 1998;78:247-306.

3 Hoffmann EK, Lambert IH, Pedersen SF: Physiology of cell volume regulation in vertebrates. Physiol Rev 2009;89:193-277.

4 Wehner F, Olsen H, Tinel H, Kinne-Saffran E, Kinne RK: Cell volume regulation: osmolytes, osmolyte transport, and signal transduction. Rev Physiol Biochem Pharmacol 2003;148:1-80.

5 Sardella E, Mola MG, Gristina R, Piccione M, Veronico V, De Bellis M, Cibelli A, Buttiglione M, Armenise V, Favia P, Nicchia GP: A Synergistic Effect of Reactive Oxygen and Reactive Nitrogen Species in Plasma Activated Liquid Media Triggers Astrocyte Wound Healing. Int J Mol Sci 2020;21:3343.

6 Lafrenaye AD, Simard JM: Bursting at the Seams: Molecular Mechanisms Mediating Astrocyte Swelling. Int J Mol Sci 2019;20:330.

7 Verkhratsky A, Parpura V, Vardjan N, Zorec R: Physiology of Astroglia. Adv Exp Med Biol 2019;1175:45-91.

8 Nagelhus EA, Ottersen OP: Physiological Roles of Aquaporin-4 in Brain. Physiol Rev 2013;93:1543-1562.

9 Chen L, König B, Liu T, Pervaiz S, Razzaque YS, Stauber T: More than just a pressure relief valve: Physiological roles of volume-regulated LRRC8 anion channels. Biol Chem 2020;400:1481-1496.

10 Wilson CS, Mongin AA: Cell Volume Control in Healthy Brain and Neuropathologies. Curr Top Membr 2018;81:385-455.

11 Pivonkova H, Hermanova Z, Kirdajova D, Awadova T, Malinsky J, Valihrach L, Zucha D, Kubista M, Galisova A, Jirak D, Anderova M: The Contribution of TRPV4 Channels to Astrocyte Volume Regulation and Brain Edema Formation. Neuroscience 2018;394:127-143.

12 Jung JS, Bhat R V, Preston GM, Guggino WB, Baraban JM, Agre P: Molecular characterization of an aquaporin cDNA from brain: Candidate osmoreceptor and regulator of water balance. Proc Natl Acad Sci U S A 1994;91:13052-13056. 


\section{Cellular Physiology Cell Physiol Biochem 2021;55(S1):196-212 \begin{tabular}{ll|l}
\hline DOI: 10.33594/000000469 2021 The Author(s). Published by \\
\hline
\end{tabular} and Biochemistry Published online: 5 November 2021 Cell Physiol Biochem Press GmbH\&Co. KG \\ Mola et al.: Interplay of Chloride and Calcium Channels with Aquaporin-4 in Differentiated Astrocytes}

13 Frigeri A, Gropper MA, Turck CW, Verkman AS: Immunolocalization of the mercurial-insensitive water channel and glycerol intrinsic protein in epithelial cell plasma membranes. Proc Natl Acad Sci U S A 1995;92:4328-4331.

14 Nielsen S, Nagelhus EA, Amiry-Moghaddam M, Bourque C, Agre P, Ottersen OP: Specialized membrane Domains for Water Transport in Glial Cells: High- Resolution Immunogold Cytochemistry of Aquaporin-4 in Rat Brain. J Neurosci 1997;17:171-180.

15 Amiry-Moghaddam M, Ottersen OP: The molecular basis of water transport in the brain. Nat Rev Neurosci 2003;4:991-1001.

16 Neely JD, Amiry-Moghaddam M, Ottersen OP, Froehner SC, Agre P, Adams ME: Syntrophin-dependent expression and localization of Aquaporin-4 water channel protein. Proc Natl Acad Sci U S A 2001;98:14108-14113.

17 Hoddevik EH, Khan FH, Rahmani S, Ottersen OP, Boldt HB, Amiry-Moghaddam M: Factors determining the density of AQP4 water channel molecules at the brain-blood interface. Brain Struct Funct 2017;222:17531766.

18 Benfenati V, Amiry-Moghaddam M, Caprini M, Mylonakou MN, Rapisarda C, Ottersen OP, Ferroni S: Expression and functional characterization of transient receptor potential vanilloid-related channel 4 (TRPV4) in rat cortical astrocytes. Neuroscience 2007;148:876-892.

19 Benfenati V, Caprini M, Dovizio M, Mylonakou MN, Ferroni S, Ottersen OP, Amiry-Moghaddam M: An aquaporin-4/transient receptor potential vanilloid 4 (AQP4/TRPV4) complex is essential for cell-volume control in astrocytes. Proc Natl Acad Sci U S A 2011;108:2563-2568.

20 Mola MG, Sparaneo A, Gargano CD, Spray DC, Svelto M, Frigeri A, Scemes E, Nicchia GP: The Speed of Swelling Kinetics Modulates Cell Volume Regulation and Calcium Signaling in Astrocytes: A Different Point of View on the Role of Aquaporins. Glia 2016;64:139-154.

21 Dunn KM, Hill-Eubanks DC, Liedtke W, Nelson MT: TRPV4 channels stimulate Ca2+-induced Ca2+ release in astrocytic endfeet and amplify neurovascular coupling responses. Proc Natl Acad Sci U S A 2013;110:61576162.

22 Toft-Bertelsen TL, Larsen BR, MacAulay N: Sensing and regulation of cell volume - We know so much and yet understand so little: TRPV4 as a sensor of volume changes but possibly without a volume-regulatory role? Channels 2018;12:100-108.

23 Kanju P, Liedtke W: Pleiotropic function of TRPV4 ion channels in the central nervous system. Exp Physiol 2016;101:1472-1476.

24 Pasantes-Morales H, Franco R, Torres-Marquez ME, Hernández-Fonseca K, Ortega A: Amino Acid Osmolytes in Regulatory Volume Decrease and Isovolumetric Regulation in Brain Cells: Contribution and Mechanisms. Cell Physiol Biochem 2000;10:361-370.

25 Kimelberg HK: Astrocytic swelling in cerebral ischemia as a possible cause of injury and target for therapy. Glia 2005;50:389-397.

26 Benfenati V, Nicchia GP, Svelto M, Rapisarda C, Frigeri A, Ferroni S: Functional down-regulation of volumeregulated anion channels in AQP4 knockdown cultured rat cortical astrocytes. J Neurochem 2007;100:87104.

27 Hyzinski-García MC, Rudkouskaya A, Mongin AA: LRRC8A protein is indispensable for swelling-activated and ATP-induced release of excitatory amino acids in rat astrocytes. J Physiol 2014;592:4855-4862.

28 Formaggio F, Saracino E, Mola MG, Rao SB, Amiry-Moghaddam M, Muccini M, Zamboni R, Nicchia GP, Caprini M, Benfenati V: LRRC8A is essential for swelling-activated chloride current and for regulatory volume decrease in astrocytes. FASEB J 2019;33:101-113.

29 Hopt A, Neher E: Highly Nonlinear Photodamage in Two-Photon Fluorescence Microscopy. Biophys J 2001;80:2029-2036.

30 Benfenati V, Caprini M, Nobile M, Rapisarda C, Ferroni S: Guanosine promotes the up-regulation of inward rectifier potassium current mediated by Kir4.1 in cultured rat cortical astrocytes. J Neurochem 2006;98:430-445.

31 Nicchia GP, Rossi A, Mola MG, Procino G, Frigeri A, Svelto M: Actin Cytoskeleton Remodeling Governs Aquaporin-4 Localization in Astrocytes. Glia 2008;56:1755-1766.

32 Posati T, Pistone A, Saracino E, Formaggio F, Mola MG, Troni E, Sagnella A, Nocchetti M, Barbalinardo M, Valle F, Bonetti S, Caprini M, Nicchia GP, Zamboni R, Muccini M; Benfenati V: A Nanoscale Interface Promoting Molecular and Functional Differentiation of Neural Cells. Sci Rep 2016;6:31226. 


\section{Cellular Physiology Cell Physiol Biochem 2021;55(S1):196-212 \begin{tabular}{l|l|l}
\hline DOI: 10.33594/000000469 2021 The Author(s). Published by \\
\hline
\end{tabular} and Biochemistry Published online: 5 November 2021 Cell Physiol Biochem Press GmbH\&Co. KG \\ Mola et al.: Interplay of Chloride and Calcium Channels with Aquaporin-4 in Differentiated Astrocytes}

33 Jo AO, Ryskamp DA, Phuong TTT, Verkman AS, Yarishkin O, MacAulay N, Križaj D: TRPV4 and AQP4 Channels Synergistically Regulate Cell Volume and Calcium Homeostasis in Retinal Müller Glia. J Neurosci 2015;35:13525-13537.

34 Yang J, Vitery M del C, Chen J, Osei-Owusu J, Chu J, Qiu Z: Glutamate-Releasing SWELL1 Channel in Astrocytes Modulates Synaptic Transmission and Promotes Brain Damage in Stroke. Neuron 2019;102:813-827.

35 Mola MG, Nicchia GP, Svelto M, Spray DC, Frigeri A: Automated Cell-Based Assay for Screening of Aquaporin Inhibitors. Anal Chem 2009;81:8219-8229.

36 Farinas J, Simanek V, Verkman AS: Cell volume measured by total internal reflection microfluorimetry: application to water and solute transport in cells transfected with water channel homologs. Biophys J 1995;68:1613-1620.

37 Solenov E, Watanabe H, Manley GT, Verkman AS: Sevenfold-reduced osmotic water permeability in primary astrocyte cultures from AQP-4-deficient mice, measured by a fluorescence quenching method. Am J Physiol Cell Physiol 2004;286:426-432.

38 Chen Z, Zhang Z, Gu Y, Bai C: Impaired migration and cell volume regulation in aquaporin 5-deficient SPC-A1 cells. Respir Physiol Neurobiol 2011;176:110-117.

39 Peckys DB, Kleinhans FW, Mazur P: Rectification of the water permeability in COS-7 cells at 22,10 and $0^{\circ} \mathrm{C}$. PLoS One 2011;6:e23643.

40 Hamill OP, Marty A, Neher E, Sakmann B, Sigworth FJ: Improved patch-clamp techniques for highresolution current recording from cells and cell-free membrane patches. Pflügers Arch 1981;391:85-100.

41 Benfenati V, Caprini M, Nicchia GP, Rossi A, Dovizio M, Cervetto C, Nobile M, Ferroni S: Carbenoxolone inhibits volume-regulated anion conductance in cultured rat cortical astroglia. Channels 2009;3:323-336.

42 Heo J, Meng F, Hua SZ: Contribution of Aquaporins to Cellular Water Transport Observed by a Microfluidic Cell Volume Sensor. Anal Chem 2008;80:6974-6980.

43 Fenton RA, Moeller HB, Nielsen S, De Groot BL, Rützler M: A plate reader-based method for cell water permeability measurement. Am J Physiol Renal Physiol 2010;298:224-230.

44 Gao X, Wu L, O’Neil RG: Temperature-modulated diversity of TRPV4 channel gating. J Biol Chem 2003;278:27129-27137.

45 Butenko O, Dzamba D, Benesova J, Honsa P, Benfenati V, Rusnakova V, Ferroni S, Anderova M: The Increased Activity of TRPV4 Channel in the Astrocytes of the Adult Rat Hippocampus after Cerebral Hypoxia/ Ischemia. PLoS One 2012;7:e39959.

46 Vincent F, Acevedo A, Nguyen MT, Dourado M, DeFalco J, Gustafson A, Spiro P, Emerling DE, Kelly MG, Duncton MAJ: Identification and characterization of novel TRPV4 modulators. Biochem Biophys Res Commun 2009;389:490-494.

47 Kimelberg HK: Water homeostasis in the brain: Basic concepts. Neuroscience 2004;129:851-860.

48 Borrachero-Conejo AI, Adams WR, Saracino E, Mola MG, Wang M, Posati T, Formaggio F, De Bellis M, Frigeri A, Caprini M, Hutchinson MR, Muccini M, Zamboni R, Nicchia GP, Mahadevan-Jansen A, Benfenati V: Stimulation of water and calcium dynamics in astrocytes with pulsed infrared light. FASEB J 2020;34:65396553.

49 Nicchia GP, Frigeri A, Liuzzi GM, Svelto M: Inhibition of AQP4 expression in astrocytes by RNAi determines alterations in cell morphology, growth, and water transport and induces changes in ischemia related genes. FASEB J 2003;17:1508-1510.

50 Nicchia GP, Srinivas M, Li W, Brosnan CF, Frigeri A, Spray DC: New possible roles for aquaporin-4 in astrocytes: cell cytoskeleton and functional relationship with connexin43. FASEB J 2005;19:1674-1676.

51 Liedtke W, Choe Y, Martí-Renom MA, Bell AM, Denis CS, Sali A, Hudspeth AJ, Friedman JM, Heller S: Vanilloid Receptor-Related Osmotically Activated Channel (VR-OAC), a Candidate Vertebrate Osmoreceptor. Cell 2000;103:525-535.

52 Vriens J, Watanabe H, Janssens A, Droogmans G, Voets T, Nilius B: Cell swelling, heat, and chemical agonists use distinct pathways for the activation of the cation channel TRPV4. Proc Natl Acad Sci U S A 2004;101:396-401.

53 Thrane AS, Rappold PM, Fujita T, Torres A, Bekar LK, Takano T, Peng W, Wang F, Thrane VR, Enger R, Haj-Yasein NN, Skare Ø, Holen T, Klungland A, Ottersen OP, Nedergaard M, Nagelhus EA: Critical role of aquaporin-4 (AQP4) in astrocytic Ca2+ signaling events elicited by cerebral edema. Proc Natl Acad Sci U S A 2011;108:846-851. 


\section{Cellular Physiology Cell Physiol Biochem 2021;55(S1):196-212 \begin{tabular}{ll|l|l|l} 
DOI: 10.33594/000000469 & 2021 The Author(s). Published by
\end{tabular} and Biochemistry Published online: 5 November 2021 Cell Physiol Biochem Press GmbH\&Co. KG \\ Mola et al.: Interplay of Chloride and Calcium Channels with Aquaporin-4 in Differentiated Astrocytes}

54 Haj-Yasein NN, Jensen V, Østby I, Omholt SW, Voipio J, Kaila K, Ottersen OP, Hvalby Ø, Nagelhus EA: Aquaporin-4 regulates extracellular space volume dynamics during high-frequency synaptic stimulation: A gene deletion study in mouse hippocampus. Glia 2012;60:867-874.

55 Saracino E, Cirillo V, Marrese M, Guarino V, Benfenati V, Zamboni R, Ambrosio L: Structural and functional properties of astrocytes on PCL based electrospun fibres. Mater Sci Eng C Mater Biol Appl 2021;118:111363.

56 Saracino E, Maiolo L, Polese D, Semprini M, Borrachero-Conejo AI, Gasparetto J, Murtagh S, Sola M, Tomasi L, Valle F, Pazzini L, Formaggio F, Chiappalone M, Hussain S, Caprini M, Muccini M, Ambrosio L, Fortunato G, Zamboni R, Convertino A, et al.: A Glial-Silicon Nanowire Electrode Junction Enabling Differentiation and Noninvasive Recording of Slow Oscillations from Primary Astrocytes. Adv Biosyst 2020;4:e1900264.

57 Simone L, Pisani F, Mola MG, De Bellis M, Merla G, Micale L, Frigeri A, Vescovi AL, Svelto M, Nicchia GP: AQP4 aggregation state is a determinant for glioma cell fate. Cancer Res 2019;79:2182-2194.

58 Ernest NJ, Weaver AK, Van Duyn LB, Sontheimer HW: Relative contribution of chloride channels and transporters to regulatory volume decrease in human glioma cells. Am J Physiol Cell Physiol 2005;288:1451-1460. 